\title{
Cartas de navegação: planejamento museológico em mar revolto
}

\author{
Manuelina Maria Duarte Cândido ${ }^{1}$
}

\begin{abstract}
Resumo
Este texto apresenta uma discussão em torno das idéias de planejamento museu como uma carta náutica. Seu objetivo é trazer o debate atual sobre a gestão de museus para um maior escopo de instituições, argumentando que pequenos museus também devem incluir a gestão de suas preocupações. Metodologicamente entendemos Museologia como ciência social aplicada, isso significa que ela é capaz de interferir na realidade e também é baseada em uma forte teoria, que deve estar ligadas com as práticas, a fim de qualificar os museus e, por outro lado, a realidade deve também melhorar a teoria. As cartas náuticas precisam ser flexíveis, bem como o planejamento museológico. Como a Museologia pode ajudar os museus a não se perderem em critérios de gestão que vêm de outras áreas?
\end{abstract}

Palavras-chave

Gestão de museus, planejamento museológico, Museologia, Museologia Aplicada

\section{Abstract}

This text presents a discussion around the ideas of museum planning as a nautical chart. Its aim is to bring the actual debate about museums management for a widest scope of institutions, arguing that small museums should also to include management in their concerns. Methodologically we understand Museology as applied social science, that means it is able to interfere in the reality and also is based in strong theory that should be linked with practices in order to qualify museums and, in the

\footnotetext{
${ }^{1}$ Profa. de Museologia da FCS/UFG - Brasil

Pós-Doutoranda na Université Paris III Sorbonne Nouvelle - França
} 
other hand, the reality improve the theory too. Nautical chart need to be flexible as well as museological planning. How Museology can help museums to not be lost in management criterias coming from other areas?

\section{Keywords}

Museums management, museological planning, Museology, Applied Museology

O presente artigo se propõe a tratar de algumas ideias da tese de doutorado defendida na Universidade Lusófona de Humanidades e Tecnologias em fevereiro de 2012, avançando em direção a um balanço crítico do estado da arte da gestão de museus, especialmente no Brasil, mais de dois anos após a defesa. Vale ressaltar que a tese, intitulada Gestão de museus e o desafio do método na diversidade: diagnóstico museológico e planejamento (Duarte Cândido, 2011), tornou-se um livro que vai em sua segunda edição (Duarte Cândido, 2014) e tem merecido algum destaque especialmente pela escassez de material sobre gestão de museus em língua portuguesa.

A problemática da gestão de museus tem se tornado central também em muitos outros fóruns de discussão e não parece permitir que mesmo discussões que se pretendam mais teóricas ou programáticas passarem ao seu largo. Foi assim que no recente 370 Simpósio Internacional do ICOFOM ${ }^{2}$, ao fazer um balanço final das perspectivas museais com base especialmente no que apareceu nas apresentações do evento, o canadense Yves Bergeron (comunicação oral) sublinhou a fragilidade financeira dos museus como um grande desafio, especialmente para os museus que ele chamou de intermediários, ou seja, aqueles que nem estão na lógica da mercantilização, do turismo de massas e dos seletos museus nacionais que podem ser privilegiados por

\footnotetext{
2 Realizado na Universidade Sorbonne, em Paris, França, de 05 a 09 de junho de 2014.
} 
apoio do Estado e das grandes empresas, nem são os pequenos museus comunitários que atuam com baixíssimo custo, apoiados no voluntariado de um pequeno grupo de pessoas que compreende ser beneficiária e responsável pela existência do museu.

A pesquisa que resultou na tese vinculou-se à Linha de Investigação Museologia, SSME, Qualidade e Avaliação em Museus, sendo SSME (Services Science, Management and Engineering) considerada pela IBM como o estudo das "dinâmicas configurações de pessoas, tecnologias, organizações e informações compartilhadas que criam e oferecem valor aos clientes, fornecedores e outras partes interessadas - e como eles podem utilizar as práticas de gestão e engenharia para aperfeiçoá-las." (IBM, s. d.)

Associando as reflexões de Moutinho (2008) sobre museus como prestadores de serviços a uma leve aproximação com as engenharias, buscamos contribuir para a qualidade e gestão em museus a partir da construção de uma estrutura conceitual mais sólida para o campo da Museologia. A concepção de uma matriz para diagnóstico museológico seria então baseada nesta engrenagem formulada a partir de um conhecimento amplo e profundo do campo, tanto em termos de conceitos como de repertório de experiências, pois o diagnosticador é um conhecedor e, portanto, para diagnosticar problemas e potencialidades em museus é necessário ao profissional um conhecimento museológico capaz de fundamentar e aguçar "elementos imponderáveis: faro, golpe de vista, intuição" (Ginzburg, 1989, p. 179).

O autor defende o paradigma indiciário, segundo o qual a intuição nada tem a ver com irracionalismo, mas age com base em indícios. O diagnosticador usa o faro, a intuição, como óculos construídos a partir do seu conhecimento do campo, que tornam seu olhar mais sensível aos problemas e às potencialidades de cada caso concreto. Além do olhar crítico sobre o problema, a compreensão da Museologia 
como disciplina aplicada leva a propor caminhos, experimentar soluções, avaliar e retroalimentar a teoria. A Museologia teórica e prática é apontada como caminho possível para a qualificação das instituições museológicas a partir de procedimentos de avaliação e planejamento contínuos. Diferentemente da aplicação direta de métodos de gestão criados em outras áreas para os mais diferentes tipos de organizações, nossa matriz propõe parâmetros museológicos para a avaliação ou diagnóstico museológico.

Também estamos entendendo que a Museologia trata não apenas de museus-instituições, mas de processos de musealização, considerados como aqueles que ocorrem a partir de uma seleção e atribuição de sentidos feita dentro de um universo patrimonial amplo ${ }^{3}$, resultando em um recorte formado por um conjunto de indicadores da memória (referências patrimoniais) tangíveis ou intangíveis, naturais ou artificiais, indistintamente. Feita a seleção, estas referências ingressam em uma cadeia operatória que corresponde ao universo de aplicação da Museologia (museografia). Preservação, portanto, é tomada como equivalente a processo de musealização, e é realizada pela aplicação de uma cadeia operatória formada por procedimentos técnicocientíficos de salvaguarda e de comunicação patrimoniais, em equilíbrio.

Na definição de fato museal de Waldisa Rússio cabem diferentes abordagens dos quatro elementos a serem considerados: a relação (emoção/razão) entre o homem, sujeito que conhece, o objeto, parte da realidade, em um cenário institucionalizado, o museu. A própria autora esclarece que a sua noção de instituição cobre tanto o grande como o pequeno museu e o ecomuseu (Rússio, 1981, in

3 Tal concepção é recorrente na literatura museológica há décadas, inclusive amplamente discutida em termos como museu integral ou integrado (ver Duarte Cândido, 2003) e apenas reforçada a partir da Convenção do Patrimônio Imaterial de 2003. 
Bruno, 2010, p. 123-124).

O quadro a seguir sintetiza estas ideias.

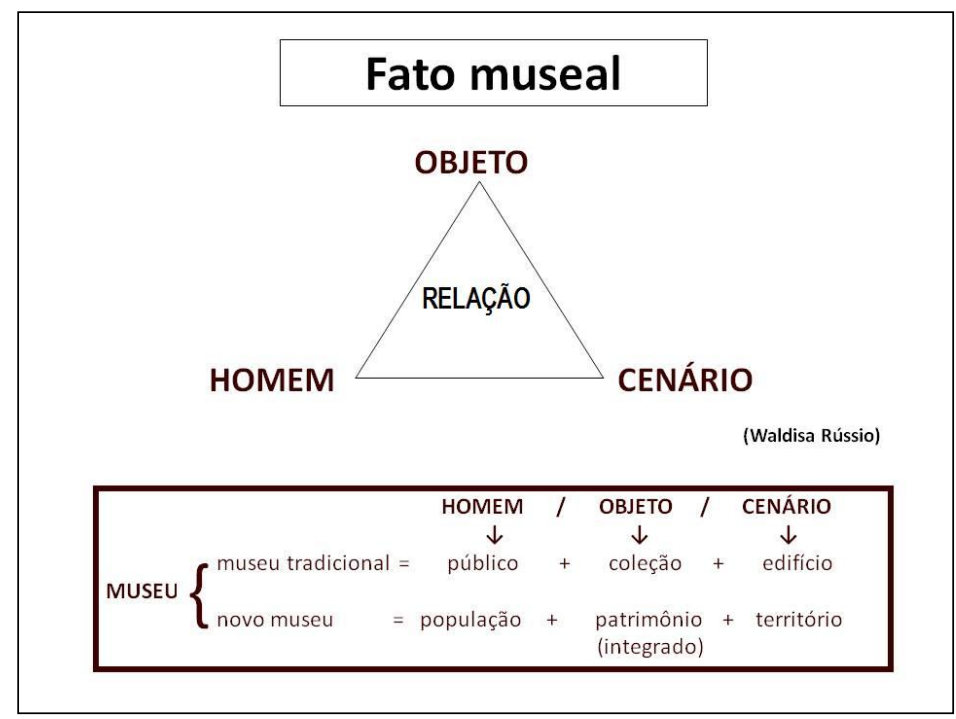

Figura 1: Quadro-síntese: a tríade homem-objeto-cenário (fato museal) nos museus tradicionais e nos novos modelos museais (Manuelina Duarte, 2004 - material de aula)

Segundo Neves, "quando se refere ao museu como um 'cenário institucionalizado' onde se realiza o fato museal, Waldisa [Rússio] pensa o conceito de institucionalização no âmbito da Sociologia, de forma muito mais ampla que aquele do senso comum, ou seja, '(...) com o significado de criado, querido ou reconhecido pela comunidade ou a sociedade'. $\mathrm{E}$ questiona se os museus são resultado da vontade social (ou mesmo de segmentos da comunidade), se estão envolvidos com as comunidades, e se são respeitados e queridos. Caso contrário, a 'institucionalização' é apenas nos termos do jurídico-formal." (Neves, 2011, p. 29) Portanto, calcadas neste pensamento, as noções de museu e de instituição com as quais estamos lidando aqui são amplas e dinâmicas, para além do modelo considerado museu tradicional. 
Falar de métodos em um cenário tão diversificado foi o grande desafio da tese, especialmente em se tratando de um tema cuja bibliografia costuma ser dirigida apenas para os museus mais tradicionais e com maiores recursos (Ambrose \& Paine, 2012; Lord \& Lord, 2008; Lord \& Market, 2007; Riebe, 2007; Serra, 2007; Boylan, 2004; Mason, 2004; Genoways \& Ireland, 2003; Davies, 2001; Moore, 1998; Burcaw, 1997; Fopp, 1997). Raros autores se dedicam a demonstrar necessidades comuns a todos os tipos de museus no campo da gestão e da qualidade (Moutinho, 1993; Mayrand, 2006; Victor, 2006a e 2006b; Varine, 2011).

Por outro lado, é um tabu questionar museu sobre os recursos que consomem no desempenho de suas funções. Entretanto, no contexto atual de recuo do Estado na manutenção de setores como a cultura, François Mairesse (2011, p. 299) alerta para a concorrência e o risco de saturação da capacidade de sustentação dos museus, em número cada vez maior, mas concorrendo por recursos em diminuição. O autor é profícuo em análises sobre a diminuição das políticas públicas para a cultura e notadamente os museus após o estabelecimento das diretrizes neoliberais da Escola de Chicago, cujo efeito é, no limite, a transformação do visitante de museu em um consumidor, influenciando até mesmo a predominância da língua inglesa na literatura do setor, por ser mais afinada com as novas demandas e diretrizes (Mairesse, 2012, p. 22). Segundo o autor, a maneira anglo-saxônica de pensar museus se impôs, desde a década de 1990, em todo o mundo (idem, p. 22 e 23).

\section{Mar revolto, barco pequeno: um risco a mais}

A concentração de recursos em poucas instituições e o distanciamento cada vez maior entre a qualidade geral do setor e a excelência de algumas poucas de instituições são o resultado mais evidente da nova ordem. Enquanto alguns 
poucos museus seguem seu cruzeiro, alguns transatlânticos afundam $^{4}$ e pequenos barcos ficam à deriva (ou os intermediários, como disse Bergeron, já citado, para diferenciá-los dos museus comunitários). Estamos tomando de empréstimo a metáfora de Moore:

"En un mundo de cambios rápidos un museo pequeño podría describirse como un pequeño bote de vela en un mar embravecido, controlado en gran medida por fuerzas externas.

En dicha situación, es especialmente vital que el museo tenga un plan estratégico, un mapa y ayudas para la navegación, para intentar navegar a través de aguas tan procelosas." (Moore, apud Lacasta; Peraile, 2006, p. 48)

Em um momento em que cada vez aparecem mais expressões como museum crowdsourcing, museums branding (e co-branding) ou museografia low cost ${ }^{5}$, parece evidente que os museus estão tendo de lidar com demandas jamais imaginadas em suas origens, mas os profissionais da área têm muitas vezes uma relação conflituosa indicadores de avaliação, especialmente os quantitativos. Se isto causa espécie entre profissionais de museus, é ainda mais problemático nas realidades que envolvem iniciativas comunitárias, amadores e, em especial, governos de pequenas localidades. O pequeno porte dos museus não deveria, entretanto, ser argumento para protelar o planejamento, pois sem planejamento cada museu fica à mercê das forças externas, e a fragilidade dos pequenos museus torna-os ainda mais vulneráveis.

O planejamento institucional ou plano museológico,

\footnotetext{
${ }^{4}$ A ideia de um transatlântico pesado e difícil de governar é uma releitura dos mastodontes longevos, prolíficos e bulímicos de Balerdi (2008), museus capazes de ingerir a tudo indiscriminadamente para depois se envergonhar desses excessos e escondê-los em reservas técnicas ou mesmo provocar o vômito, realizando descartes.

${ }^{5}$ Percebe-se que, de fato, no que tange à gestão de museus, até mesmo o uso dos termos sem tradução reflete a primazia da influência anglófila.
} 
como quer a legislação brasileira, funcionaria, então, como uma carta de navegação, que tem entre suas propriedades a flexibilidade, pois mapeia obstáculos e correntes, sugerindo um percurso para atingir o objetivo final da viagem, mas o trajeto pode ser revisto para incorporar dados que surjam em seu transcurso, como barreiras imprevistas ou um vento favorável que não era esperado. Assim, o planejamento ao mesmo tempo em que sinaliza aonde se quer chegar e como, precisa ter a flexibilidade para acolher e utilizar as informações que aparecem durante o percurso e que não estavam previstas.

O planejamento não pode ser tão cerceador que impeça o museu de ser oportunista no sentido de aproveitar conveniências que não estavam previstas, mas surgiram no decorrer do percurso. Os planos devem permitir sempre um grau de espontaneidade (Moore, 2005, p. 43).

Os profissionais dos museus precisam pensar 0 planejamento assim, como um documento que norteia, mas não amarra, não é inflexível. E a preocupação com gestão precisa ser reforçada na formação em Museologia (Duarte Cândido, 2012).

A profissionalização nos museus remonta ao séc. XIX e à criação das primeiras associações, como a britânica, criada em 1889 (Mairesse in Desvallées \& Mairesse, 2011, p. 178). Após a crise do petróleo na década de 1970, o mundo entrou em uma fase marcada pela incerteza, e os museus não escaparam à nova realidade, acordando para a necessidade de pensar sobre gestão e marketing para sobreviver à recessão ${ }^{6}$.Além das primeiras publicações enfocando temas

6 Segundo Karina Pronitcheva (comunicação oral no 370 Simpósio Internacional do ICOFOM, Paris, 2014), a primeira exposição blockbuster com patrocínio privado ocorreu no Museu de Arte Moderna de Nova lorque em 1967, e logo as exposições temporárias começaram a ser pensadas já dentro de uma nova lógica, a de gerar fundos para os museus. Para alcançar este objetivo e. segundo a mesma pesquisadora russa, inspirados na experiência do filme Star Wars, em que George Lucas 
como captação de recursos, mercado e planejamento estratégico, esta época viu uma ascensão sem precedentes da avaliação de museus por olhares externos, incluindo auditorias. Esta forma de gerir ainda não é realidade ampla nos mais de três mil museus brasileiros, especialmente os museus municipais, embora nos grandes centros já se avaliem com maior transparência o custo de manter o museu e os casos de museus com caixa negativo (IPEA, 2007, p. 34).

Os públicos, por sua vez, passaram a ser mais exigentes, diante do aumento da oferta cultural, exigindo que os museus saiam de sua posição de receptores passivos e instituições cuja existência e finalidades são indiscutíveis. Especialistas em economia que se debruçam sobre o caso dos museus, afirmam que comparativamente à enorme riqueza patrimonial que conservam, eles possuem orçamentos parcos (Mairesse, 2011, p. 191). No entanto, sua resistência a mensurar suas despesas e seus valores é evidente. Muitos museus dependentes de instâncias estatais sequer têm noção do seu custo anual ${ }^{7}$, pois ao mesmo tempo queixam-se de não ter dotações orçamentárias independentes, mas se desresponsabilizam de controlar gastos operacionais (despesas com telefonia, eletricidade, segurança e limpeza, em geral pagas por outros órgãos), de manutenção e mesmo com salários. Estes museus não possuem recursos para investimentos pequenos em programação e outras necessidades, mas são alheios ao custo do museu e talvez se fizessem a conta percebessem que a relação custo/benefício

introduziu uma nova maneira de financiamento, que fez com que todo o filme fosse pensado como uma marca a ser explorada comercialmente em termos de venda de produtos alusivos à produção, os museus entram na lógica do gerenciamento de marcas e em uma exploração comercial cada vez maior de sua imagem.

${ }^{7}$ Estamos nos referindo aqui especialmente aos pequenos museus e não aos museus standard ou aqueles geridos pelo terceiro setor, que já têm a transparência financeira e a obtenção de metas como premissa para seus contratos de gestão. 
da existência do museu não se equilibra quando ele apenas abre as portas e recebe poucos visitantes por não ter uma oferta mais atraente e estimulante para o público usuário.

A importância de mensurar separadamente o custo operacional do museu e a sua necessidade de investimento fica ainda mais evidente quando pensamos que a política de editais e de incentivos fiscais para patrocínio de museus, considerada verdadeira panacéia para suas dificuldades financeiras, atua somente sobre o investimento em ações pontuais, mas não sustenta as instituições no dia-a-dia, além de beneficiar uma parte muito pequena dos museus em funcionamento. E ainda assim, criam-se museus sem estudos de viabilidade, havendo o citado incômodo em tocar nestas preocupações mundanas do mundo dos negócios quando se trata de uma instituição cuja função social é quase sagrada, de tão indiscutível ${ }^{8}$.

Os museus ainda têm estado em geral desatentos a determinadas forças, mas cada vez mais é evidente que eles não podem fechar os olhos a estes aspectos de sua existência. O planejamento estratégico vai sendo reforçado como instrumento fundamental da gestão dos museus, envolvendo ao mesmo tempo os objetivos da instituição e suas estratégias para alcançá-los.

\section{Especificidades, desafios e razões da avaliação e do planejamento em museus}

Uma característica do planejamento é a criação de indicadores de avaliação, associados ou não ao

\footnotetext{
${ }^{8}$ Nosso argumento não intenciona fragilizar a percepção de relevância dos museus na sociedade, mas revolver o pó que guardamos embaixo do tapete e nos manter alertas por estas provocações, ao fato de que estamos gerando não somente uma herança para as futuras gerações, mas também despesas e responsabilidades, cada vez que criamos museus. Desta forma, não podemos ser poupados de ao menos iniciar uma reflexão racional sobre estes temas com os quais nós, geração presente de profissionais da área, ainda estamos aprendendo a lidar e a colocar em pauta.
} 
estabelecimento de protocolos e estratégias de controle dos padrões de qualidade. Entretanto, falar de padrões ainda é um problema na área dos museus, devido à sua resistência em se verem avaliados, especialmente comparados, o que retardaria nesses tipos de organizações a entrada de métodos já consolidados em outras áreas, como o "benchmarking", não sem adequações. Por exemplo, na avaliação de museus o controle é, preferencialmente, interno; e a instituição compara sua performance com os objetivos ou com suas performances anteriores, mas raramente com as de outras instituições similares (Mairesse, 2011, p. 186)

A avaliação é essencial não apenas para identificar problemas como para precisar o valor da instituição. Arredios a ela, os museus deixam de mensurar seu impacto na geração de riquezas, seja pela produção de conhecimento científico, seja pela movimentação de pessoas e, portanto, de receitas. Na Europa existe um cálculo de que cada turista estrangeiro visitando uma exposição coloca 150 euros por dia na economia local (idem, p. 187). No Brasil desconhecemos estudos semelhantes e sabemos que os museus não têm grande aproximação com o setor de turismo, que defendemos aqui não como público prioritário, mas como um dos públicos possíveis muitas vezes esquecido pelos museus brasileiros. Mas já soubemos de um museu que, pressionado pela instituição mantenedora (privada) a adotar algum parâmetro quantitativo de avaliação, passou medir a mídia espontânea gerada para a mantenedora pelas menções ao museu na imprensa e nas redes sociais, e conseguiu com isto ampliar sua dotação orçamentária, que era inferior ao valor do espaço de divulgação obtido sem custos adicionais.

O planejamento institucional, exigido agora no Estatuto de Museus nos termos do Plano Museológico, é já uma estratégia consolidada de gestão, incluindo pelo menos duas

\footnotetext{
${ }^{9}$ Algumas exceções aparecem, como o livro "Benchmarking im museum" (Riebe, 2007).
} 
modalidades, a que Lord \& Lord (2008, p. 63) se referem pelos nomes Plano Diretor (com horizonte de implementação entre 10 e 20 anos), e Plano Estratégico ${ }^{10}$, mais calcado em curto prazo (3 a 5 anos ${ }^{11}$ ). Para estes autores, o Plano Diretor deve incluir:

- plano institucional

- estudo de público

- estudo de coleções

- plano de atividades

- estratégia de comercialização

- plano de pessoal

- plano arquitetônico

- estudo de custos financeiros

- previsão de ingressos financeiros

- estratégia de financiamento

- cronograma (idem, p. 63-64)

Ou seja, há uma combinação de elementos de diagnóstico da situação presente do museu e de projeção no futuro, ou planejamento.

O planejamento institucional é fundamental por várias razões:

- facilita a tomada de decisões;

- leva a maior eficiência e eficácia;

- permite melhor argumentação junto a mantenedores, patrocinadores e à sociedade em geral (pode fundamentar estratégias de marketing);

- busca consistência, evitando contradições internas;

${ }^{10}$ Por sua vez, é desdobrado em planejamento operacional ano a ano, que é o que mais usualmente nossas instituições fazem na execução de orçamentos anuais e de projetos.

${ }^{11}$ Este número pode variar de acordo com o porte da instituição, chegando até mais que 5 anos em instituições de grande porte. Porém, em um mundo em rápida transformação, o prazo maior pode tornar o plano inexeqüível de acordo com novos contextos. Mas sempre a descrição em detalhes será apenas para o primeiro ano. 
- auxilia no comprometimento, motivação e orientação da equipe;

- estabelece metas para uma futura avaliação.

Devemos cuidar, entretanto, de realizar um planejamento exeqüível e não irreal, ao mesmo tempo não simplório, mas também não tão 'amarrado' que impeça adaptações. Muito pouco da bibliografia de planejamento estratégico está dedicada diretamente a museus ou mesmo instituições sem fins lucrativos, sendo necessário um olhar crítico e não uma transposição direta dos formatos e metodologias.

No Brasil a obrigatoriedade de planejamento está prevista no marco legal do setor, o Estatuto de Museus. Porém, é importante que a equipe da instituição se referencie no documento de planejamento em todas as suas ações, que o consulte e atualize cotidianamente, não apenas o realize para cumprir uma obrigação legal e depois o deixe esquecido em suas gavetas. É preciso se lançar ao mar e reavaliar sistematicamente a carta de navegação.

\section{Diagnóstico museológico e planejamento: o campo de projeção da Museologia \\ Estamos enfatizando neste texto a indissociabilidade entre diagnóstico planejamento e fazer museal, a partir da compreensão da Museologia como disciplina aplicada, em que para além da análise dos fatos museais e fenômenos museológicos, trabalhamos também com acompanhamento, proposição, implantação, avaliação e qualificação de processos de musealização, conforme detalhado no quadro a seguir:}




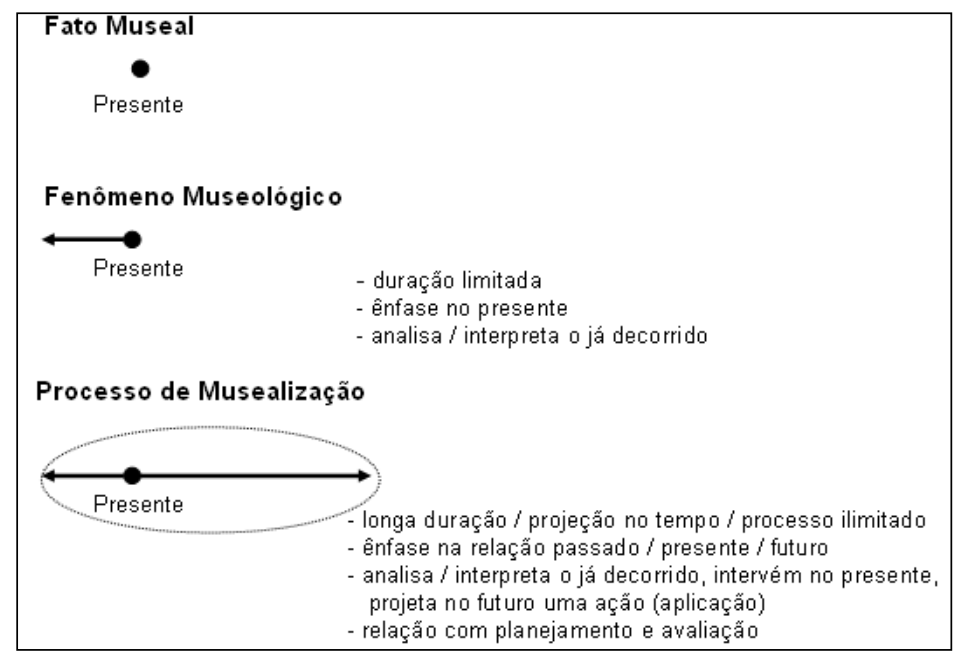

Figura 2: Encadeamento Fato Museal / Fenômeno Museológico / Processo de Musealização (Duarte Cândido, 2011, 2014)

Tanto para o diagnóstico como para o planejamento de museus propusemos uma matriz desenvolvida com critérios museológicos (Duarte Cândido, 2014), que por sua vez se inspirou no estudo de outras matrizes e modelos provenientes de diversas áreas, algumas mais próximas e outras mais distantes do universo de aplicação aos museus. A metodologia de avaliação mais aplicada ao universo dos museus a nosso ver tem sido a matriz SWOT, desenvolvida, ao longo das décadas de 1960 e 1970 por Albert Humprey, da Universidade de Stanford, utilizando dados empresariais baseados na Fortune 500. Segundo Serrano (2011), embora muitas fontes creditem a autoria a Kenneth Andrews e Roland Christensen, então professores da Harvard Business School, a obra deles não traz referências à SWOT anteriores às de Humprey.

Outras matrizes que integraram a nossa pesquisa foram a formulada para a gestão de museus por Lord \& Lord (2008), 
o modelo para qualidade em museus de Heike Riebe (2007), o "Balancing Act" de Lord \& Markert (2007), além de material procedente do mundo da administração e engenharia de qualidade, como o modelo de processos da série de normas ISO e a relação entre programas e projetos proposta por (Pfeiffer, 2000). No final, o que nos interessava era gerar uma nova matriz que fosse específica para museus e dissesse muito de nossas concepções e opções relativas ao campo específico da Museologia.

A matriz resultante apresenta a possibilidade de múltiplas leituras, como detalhado em Duarte Cândido (2011, 2014). Ela pode ser combinada, para o diagnóstico museológico, com elementos da SWOT, por exemplo, elencando pontos fortes e fracos dos fatores internos e externos que afetem cada um dos itens nela destacados. Para planejamento esta matriz sugere também um encadeamento lógico e operacional.

Os aspectos considerados a priori como elementos da gestão museológica por outros autores são a gestão das coleções, a administração financeira da instituição ou a gestão de pessoal e das instalações. Ao mesmo tempo em que estes conhecimentos são necessários, argumentamos que há formas específicas de usá-los e que eles precisam ser coordenados com um profundo conhecimento da teoria e dos métodos da Museologia, da história e da realidade das instituições museais, envolvendo necessariamente domínio teórico-prático por parte de quem está envolvido com os processos de criação, avaliação e revitalização de museus, e com seu gerenciamento cotidiano (não no sentido de um cargo de direção apenas, pois adotamos a ideia de uma gestão baseada na subisidiariedade, como explicitado a seguir).

Ao longo deste texto empreendemos a defesa de uma gestão museológica do museu, diferente da administração meio, realizada por profissionais muitas vezes exteriores ao 
PROGRAMAÇÃO OU PLANO MUSEOLÓGICO

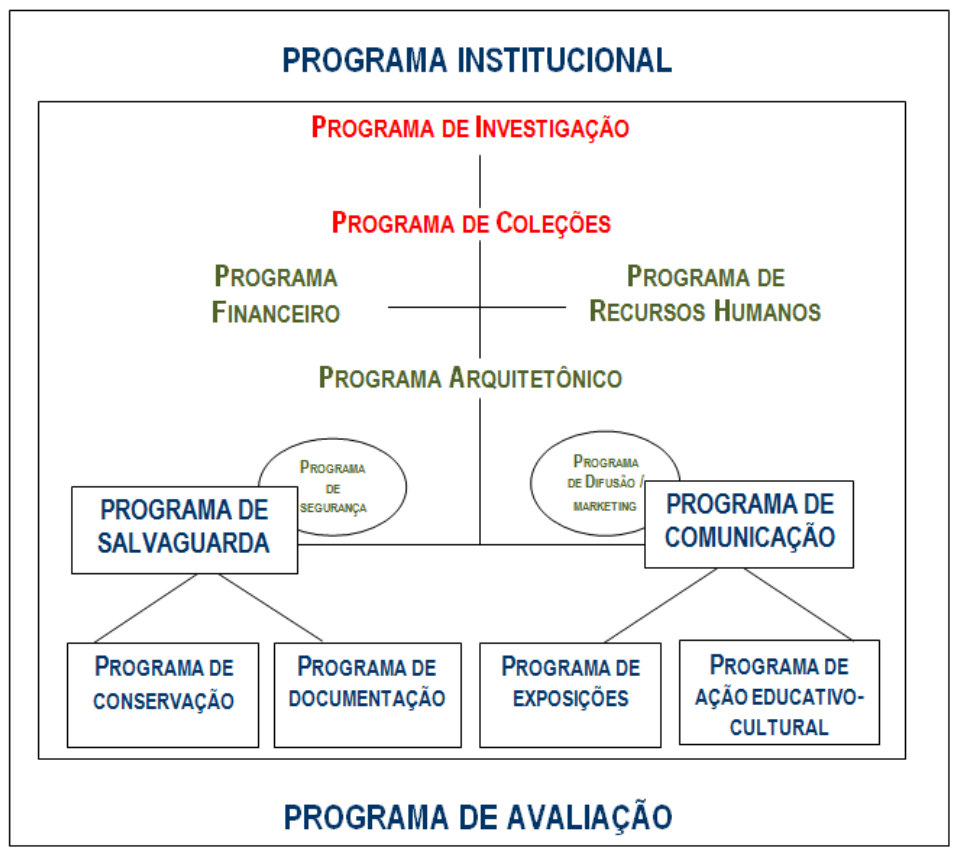

Figura 3: Matriz para diagnóstico museológico e planejamento

(Duarte Cândido, 2011, 2014)

campo da Museologia, com conhecimentos da Administração, mas nem sempre conhecedores, na mesma medida, das especificidades dos museus. O foco foram os critérios de cunho museológico que podem, juntamente com aqueles conhecimentos administrativos, qualificar o museu ou processo de musealização como um todo. Para tal, sugerimos a adoção de uma gestão institucional baseada na subsidiariedade, que implica descentralização e envolvimento de todos os trabalhadores do museu na consciência de que suas tomadas de decisão e seu profissionalismo (incluindo atualização permanente) concorrem para a boa gestão da instituição.

Com esta formulação esperamos ter contribuído não 
apenas para atrelar teoria e prática, criando uma engrenagem que explicite alguns conceitos e suas conexões, como também que possa ser rebatida no mundo dos museus, e para que todos eles, independente do seu porte, tenham minimamente um check list e uma estrutura que oriente sua gestão, tanto no momento de avaliação (diagnóstico) como de planejamento. Esta matriz continuará a ser avaliada e aprimorada à luz das aplicações que funcionam como testes que geram novas reflexões e alimentam a teorização e a modelização, importantes para a afirmação da Museologia como campo científico.

\section{Referências bibliográficas:}

AMBROSE, Timothy; PAINE, Crispin. Museum Basics. 3a Ed. New York: Routledge, 2012.

BALERDI, Ignacio Díaz. "Creced y multiplicaos: el vientre del museo", in biTARTE, San Sebastian, n. 6, 1995. p. 125-137.

BOYLAN, Patrick (Ed.). Como gerir um museu: manual prático. Paris: ICOM - Conselho Internacional de Museus, 2004.

BURCAW, George Ellis. Introduction to museum work. American Association for State and Local History book series, 1997.

DAVIES, Stuart. Plano Diretor. São Paulo: Edusp; Fundação Vitae, 2001. (Série Museologia, Roteiros Práticos, 1) DUARTE CÂNDIDO, Manuelina Maria. Diagnóstico museológico e planejamento: desafios da gestão de museus. 2a Ed. Porto Alegre: Editora Medianiz, 2014.

DUARTE CÂNDIDO, Manuelina Maria. “A gestão e o 
planejamento institucional nos currículos universitários de Museologia: estudo preliminar". In: Musear, Revista do Departamento de Museologia da Universidade Federal de Ouro Preto, ano1, n. 1. Ouro Preto: UFOP, junho de 2012. p. 51-60.

DUARTE CÂNDIDO, Manuelina Maria. Gestão de museus e o desafio do método na diversidade: diagnóstico museológico e planejamento. Lisboa: Universidade Lusófona de Humanidades e Tecnologias, 2011. (Tese de doutorado em Museologia)

DUARTE CÂNDIDO, Manuelina Maria. Ondas do Pensamento Museológico Brasileiro. Lisboa: ULHT, 2003. (Cadernos de Sociomuseologia, 20).

FOPP, Michael A.. Managing museums and galleries. London: Routledge, 1997.

GENOWAYS, Hugh H.; IRELAND, Lynne M. Museum Administration: an introduction. Walnut Creek, CA: AltaMira Press, 2003.

GINZBURG, Carlo. Mitos, emblemas e sinais Morfologia e história. São Paulo: Companhia das Letras, 1989.

IBM. (s.d.). O que é SSME? Disponível online em http://www.ibm.com/br/ibm/ideasfromibm/compsci/index.p html. Acesso em 11 de outubro de 2010.

IPEA. "Cultura: museus à beira de um ataque de nervos". Revista Desafios do Desenvolvimento. Edição 33, 10/04/2007. p. 32-39. Disponível online em http://desafios.ipea.gov.br/index.php?option=com content\& view=category\&layout=blog\&id=3\&|temid=10, acesso em 25 de maio de 2013.

LORD, Gail Dexter; MARKET, Kate. The manual of strategic planning for museums. Lanham, MD: AltaMira Press, 2007.

LORD, Barry; LORD, Gail Dexter. Manual de Gestión de Museos. Barcelona: Ariel, 2008.

MAIRESSE, François. «Le musée inclusif et la 
muséologie mondialisée» (Conferência magistral). In SCHEINER, Tereza; GRANATO, Marcus; REIS, Ma. Amélia; AMBROCY, Gladys Barrios (orgs). ICOFOM LAM 2012: términos y conceptos de la museología: museo inclusivo, interculturalidad y patrimônio integral: documento de trabalho do 210 Encontro Anual do Subcomitê Regional de Museologia para a América Latina e o Caribe - ICOFOM-LAM:. Rio de Janeiro: Universidade Federal do Estado do Rio de Janeiro (UNIRIO), 2012.

MAIRESSE, François. "Gestion». in: DESVALLÉES, André \& MAIRESSE, François (dir.). Dictionnaire encyclopédique de muséologie. Paris: Armand Colin, 2011.

MAIRESSE, François. Le musée hybride. Paris: La Documentation Française, 2010. (Collection 'MuséesMondes')

MASON, Timothy. Gestão museológica: desafios e práticas. São Paulo: Edusp; Vitae; British Council, 2004. (Série Museologia, 7)

MAYRAND, Pierre. "Qu'est-ce que la qualité au juste?» In: PRIMO, Judite (coord.). XIII Encontro Nacional Museologia e Autarquias, Lisboa: Universidade Lusófona de Humanidades e Tecnologias, 2006, p. 62-66. (Cadernos de Sociomuseologia, 25).

MOORE, Kevin (Ed.). La Gestión del Museo. Gijón: Ediciones Trea, 1998.

MOORE, Kevin. "Tengo un sueño. Planificación estratégica como inspiración para los museos". In: LACASTA, Ana Azor; PERAILE, Isabel Izquierdo (coords.). Actas de las Primeras Jornadas de Formación Museológica. Museos y planificación: estrategia de futuro. Madrid: Ministerio de la Cultura, Secretaria General Tecnica, 2006. p. 39-50. 
MOORE, Kevin. "La planificación estratégica en los museos" in: MINISTERIO de Cultura (Espanha). Revista museos.es $\mathrm{n}$ - 1,2005 , p. 32-47. Disponível online em www.mcu.es/museos/docs/MC/MES/Rev1/s2 2Planificacion. pdf Acesso em 27 de outubro de 2012.

MOUTINHO, Mário (org.). Sobre o conceito de museologia social. Lisboa: Universidade Lusófona de Humanidades e Tecnologias, 1993. (Cadernos de Sociomuseologia, 1)

Moutinho, Mário. "Os museus como instituições prestadoras de serviços". In Revista Lusófona de Humanidades e Tecnologias, 12, pp. 36-43. Lisboa: ULHT. Acedido em 06 de abril de 2010 em: http://revistas.ulusofona.pt/index.php/rhumanidades/article Liew/987/808.

NEVES, Kátia Regina Felipini. A potencialidade dos lugares da memória sob uma perspectiva museológica processual: um estudo de caso. O Memorial da Resistência de São Paulo. Lisboa: Universidade lusófona de Humanidades e Tecnologias, 2011. (Dissertação de mestrado em Museologia).

RIEBE, Heike. Benchmarking im museum. Ein Managementinstrument zur qualitätssicherung. Berlin: Institut für Museumsforchung, G+H Verlag Berlin, 2007.

RÚSSIO GUARNIERI, Waldisa. "A interdisciplinaridade em Museologia" (1981). In: BRUNO, Maria Cristina Oliveira (coord.). Waldisa Rússio Camargo Guarnieri: textos e contextos de uma trajetória profissional. São Paulo: Pinacoteca do Estado, Secretaria de Estado da Cultura, Comitê Brasileiro, 2010.

SERRA, Filipe Mascarenhas. Práticas de gestão nos museus portugueses. Lisboa: Universidade Católica Editora, 2007. (Teses. Investigação)

SERRANO, Daniel Portillo. Análise SWOT - A Matriz FOFA - Análise PFOA. 09/12/2011. Disponível online em 
http://www.portaldomarketing.com.br/Artigos/Analise SWO T Matriz FOFA.htm acesso em 10 de maio de 2013.

VARINE, Hugues de. Les musées locaux du futur. Refléxions. Pontebernardo, Itália, 22 de maio de 2011. Manuscrito não publicado.

VICTOR, Isabel. A qualidade em museus, problemática a esclarecer. In: PRIMO, Judite (coord.). XIII Encontro Nacional Museologia e Autarquias: a qualidade em museus. Lisboa: Universidade Lusófona de Humanidades e Tecnologias, 2006a, p. 21-32. (Cadernos de Sociomuseologia, 25)

VICTOR, Isabel. O paradoxo do termo avaliação em museus: um problema da maior relevância para a Museologia contemporânea. In: PRIMO, Judite (coord.). XIII Encontro Nacional Museologia e Autarquias, Lisboa: Universidade Lusófona de Humanidades e Tecnologias, 2006b, p. 88-100. (Cadernos de Sociomuseologia, 25)

Legislação:

Estatuto de museus. Lei № 11.904, de 14 de janeiro de 2009. 
